\title{
Utilization of Boiler Slag from Pulverized-Coal-Combustion Power Plants in China for Manufacturing Acoustic Materials
}

\author{
Jing Li ${ }^{1, *} \mathbb{C}$, Xinguo Zhuang ${ }^{1}$, Carlos Leiva ${ }^{2}$, Celia Arenas ${ }^{2}$, Ana Cornejo ${ }^{2}$, Xavier Querol ${ }^{3}$, \\ Natalia Moreno ${ }^{3}{ }^{(0}$, Oriol Font ${ }^{3}$ and Constantino Fernández Pereira ${ }^{2}$ \\ 1 Key Laboratory of Tectonics and Petroleum Resources, China University of Geosciences, \\ Wuhan 430074, China; xgzhuang@cug.edu.cn \\ 2 Chemical and Environmental Engineering Department, Engineering School, University of Seville, \\ E-41092 Seville, Spain; cleiva@us.es (C.L.); celiagarciaarenas@gmail.com (C.A.); \\ anacornejofg@gmail.com (A.C.); pereira@esi.us.es (C.F.P.) \\ 3 Institute of Environmental Assessment and Water Research, CSIC, C/Jordi Girona 18-26, 08034 Barcelona, \\ Spain; xavier.querol@idaea.csic.es (X.Q.); natalia.moreno@idaea.csic.es (N.M.); oriol.font@idaea.csic.es (O.F.) \\ * Correspondence: jingli@cug.edu.cn
}

Received: 28 September 2020; Accepted: 28 October 2020; Published: 31 October 2020

\begin{abstract}
The potential utilization of boiler slag generated in large amounts from pulverized-coalcombustion (PCC) power plants has recently drawn much attention due to the serious problems caused to ecosystems. In order to make maximal use of the boiler slag and reduce the environmental risk it poses, this study focused on manufacturing acoustic materials using boiler slag from Chinese PCC power plants. Three promising acoustic materials were successfully manufactured from up to $80 \%$ boiler slag with different grain sizes, with the addition of $20 \%$ Portland cement. The density and compressive strength of the products were inversely proportional and the sound absorption coefficient was positively proportional to the grain size of the boiler slag. The best sound absorption coefficient was obtained in products made from the coarsest fraction of the boiler slag (MS-C). Nonetheless, all the boiler-slag-based acoustic products still demonstrated compressive strength and densities comparable to those of other acoustic materials made of Spanish bottom ash or other conventional/recycled materials. The acoustic products made from the coarsest fraction (MS-C) and medium fraction (MS-M) of the boiler slag presented good noise absorption characteristics, like those of the commercial coarse porous cement that is traditionally used as an acoustic product. Furthermore, the acoustic products were characterized by very low leach ability of potentially hazardous elements. Consequently, the manufacture of acoustic materials is a very promising application for boiler slag. On the one hand, it consumes huge amounts of boiler slag that is generated in large amounts in China. On the other hand, the acoustic products can be used extensively to produce road acoustic barriers with a high sound absorption efficiency, no significant physical or mechanical limitations and no environmental implication.
\end{abstract}

Keywords: acoustic barrier; boiler slag; sound absorption coefficients; leachable potential; PCC power plant

\section{Introduction}

The environmental problems caused by acoustic pollution are becoming more and more serious all over the world. This is a cause for much concern because of their detrimental effecton public health. Road traffic noise is one of the most common types of acoustic pollution, and it can be reduced by using noise materials. Noise materials are generally designed to reflect or absorb traffic noise. However, 
due to the various problems caused by the noise-reflecting barriers, there is a much greater need to develop noise materials that can absorb noise. This concern led to the development of many kinds of sound-absorbing materials, among which lightweight porous concrete is a common one [1].

Due to the decrease in natural resources, several types of sound-absorbing porous concrete have been developed as a substitute [2,3]. Bottom ash generated from pulverized-coal-combustion (PCC) power plants has been used widely as a good substitute for normal aggregates. Park et al. (2009) used coal bottom ash as a coarse aggregate to produce porous concrete [4]. Lee et al. (2010) successfully produced fiber-reinforced cellular concrete using large amounts of power plant bottom ash [5]. Arenas et al. (2010) were able to manufacture acoustic barriers from co-combustion bottom ash [6]. Several researchers subsequently manufactured acoustic barriers from sound-absorbing porous concrete made of coal bottom ash [7] and investigated the technical specifications of the acoustic barriers [8,9].

Boiler slag is an inorganic material generated from coal combustion in boilers at temperatures of 1500 to $1700^{\circ} \mathrm{C}$ and obtained by wet ash removal from wet bottom furnaces, with various grain sizes ranging from several millimeters to $<0.075 \mathrm{~mm}$ [10]. The grain size and durability of boiler slag make it suitable for various useful applications [11,12].Like molten bottom ash, boiler slag is expected to be a good substitute for normal aggregates, like bottom ash, in the production of acoustic barriers [13].

In recent decades, China has been the largest coal-consuming country, with a coal consumption of 81.67 exajoules in 2019 accounting for $51.7 \%$ of the total coal consumption worldwide [14]. This, consequently, gives rise to the largest volumes of coal combustion products (CCPs), including fly ash, boiler slag and flue gas desulfurization gypsum, in the world. Furthermore, the increasing accumulation of boiler slag and fly ash has caused serious problems for ecosystems. Therefore, utilization of CCPsis of great environmental and economic importance.

Fly ash from PCC power plants in Xinjiang, NW China has been used for several promising applications, e.g., synthesizing zeolites [15] and manufacturing fire-resistant panels [16] and highly insulating foam glass [17]. However, the utilization of boiler slag in Xinjiang has seldom been investigated. In the present research, utilization of the boiler slag from PCC power plants in Xinjiang to produce acoustic materials to be used for acoustic barrier manufacturing was investigated on a laboratory scale. The detailed preparation and test methodology; the physical, mechanical and acoustic properties; and the environmental features of the products were illustrated to evaluate feasibility for practical and industrial applications.

\section{Methodology}

\subsection{Materials}

Ordinary Portland cement type II (CEM II/B-L 32, $5 \mathrm{~N}$ ) and boiler slag were used as the main raw materials for manufacturing acoustic materials. Two boiler slag samples (denoted as WS and HS) were collected from two PCC power plantsin Xinjiang Province. Two normal aggregates, viz. fine aggregate (Fine A) and coarse aggregate (Coarse A), were also used as the raw materials to make a comparative study.

\subsection{Acoustic Material Preparation}

Since the critical property of boiler slag for acoustic materials is the grain size [7], a mixture of WS and HS boiler slag (MS) was used as the starting material for acoustic barriers. The MS was first sieved into three fractions with different grain sizes: $>5 \mathrm{~mm}$ (coarse MS (MS-C)), 1.25-5 mm (medium MS (MS-M)) and $<1.25 \mathrm{~mm}$ (fine MS (MS-F)).

In order to recycle as much boiler slag as possible and develop acoustic products with the greatest sound absorption and acceptable compressive strength, the authors' previous research concluded that up to $80 \%$ bottom ash could be used for the raw materials $[7,8]$.In the present study, the solid components, each with a composition of $80 \%$ one of the three MSs with different particle sizes and $20 \%$ ordinary Portland cement type II, were individually placed in a concrete mixer and blended to obtain a 
homogeneous mixture within $5 \mathrm{~min}$ (Table 1).Next, an appropriate amount of water was added to the mixture, which was mixed again to achieve a homogeneous paste. As seen in Table 1, when the grain size of the solid mixtures increased, the water/solid ratio decreased. Accordingly, coarse porous concrete (CC) paste ( $80 \%$ coarse aggregate (Coarse A)) and standard concrete (SC) paste (30\% Coarse A and $50 \%$ fine aggregate (Fine A)) were each obtained following the same procedure (Table 1).

Table 1. Composition ( $w t \%)$ of the specimens made from three fractions of mixed slag (MS) and Portland cement type II (PCII) compared with coarse porous (CC) and standard concrete (SC).

\begin{tabular}{ccccccccc}
\hline & $\begin{array}{c}\text { Grain Size } \\
(\mathbf{m m})\end{array}$ & $\begin{array}{c}\text { MS } \\
\mathbf{( \% )}\end{array}$ & $\begin{array}{c}\text { Coarse A } \\
\mathbf{( \% )}\end{array}$ & $\begin{array}{c}\text { Fine A } \\
\mathbf{( \% )}\end{array}$ & $\begin{array}{c}\text { PCII } \\
\mathbf{( \% )}\end{array}$ & $\begin{array}{c}\text { Total } \\
\mathbf{( g )}\end{array}$ & $\begin{array}{c}\text { Water } \\
(\mathbf{m L})\end{array}$ & $\begin{array}{c}\text { Water/Solid } \\
\text { Ratio (\%) }\end{array}$ \\
\hline MS-C & $\varphi>5$ & 80 & 0 & 0 & 20 & 364 & 43 & 11.8 \\
\hline MS-M & $5>\varphi>1.25$ & 80 & 0 & 0 & 20 & 400 & 60 & 15.0 \\
\hline MS-F & $1.25>\varphi$ & 80 & 0 & 0 & 20 & 400 & 142 & 35.5 \\
\hline CC & $9>\varphi>1.5$ & 0 & 80 & 0 & 20 & ND & ND & 9 \\
\hline SC & ND & 0 & 30 & 50 & 20 & ND & ND & ND \\
\hline
\end{tabular}

Abbreviations: MS, mixed slag; Fine A, fine aggregate; Coarse A, coarse aggregate; PCII, Portland cement type II; $\mathrm{ND}$, not determined.

The paste was placed in molds to prepare specimens of different shapes and sizes according to the regulations for different tests (Figure 1). The specimens were demolded after $24 \mathrm{~h}$ and left to cure under ambient environment for 30 days [7].

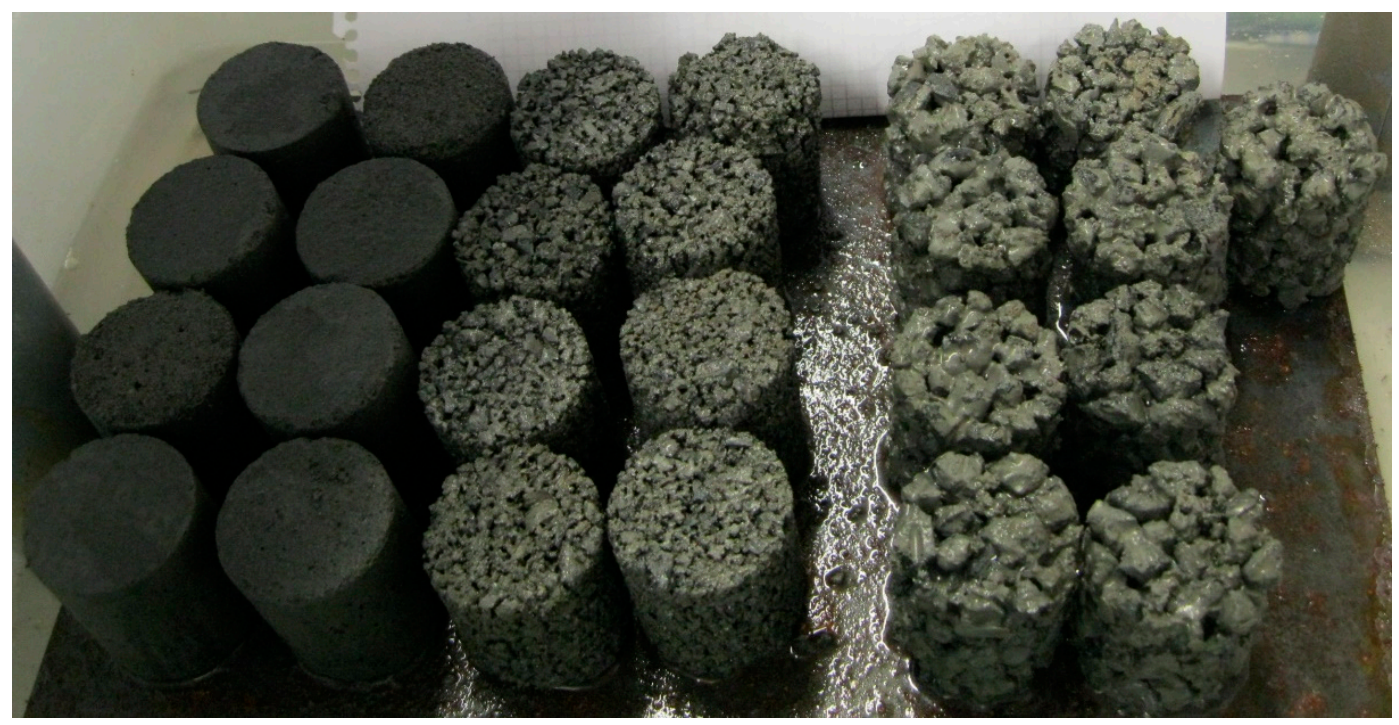

Figure 1. Specimens of the fine mixed slag (MS-F) (left), medium mixed slag (MS-M) (center) and coarse mixed slag (MS-C) (right) acoustic products.

\subsection{Characterization of the Acoustic Products}

The density $(\rho)$ of the specimens was determined by weight and volume (dimensions) measurements. Due to its high correlation to acoustic behavior, open void ratio (VR \%) of the acoustic specimens was measured following the vacuum water saturation method [18].

To evaluate the mechanical performance and stability requirements of the acoustic products, the compressive strength (Rc) was determined using 4-cm-high, 3.5-cm-diameter cylinders placed on a compressive test machine (Supezcar, MEM-102/50t) according to ASTM C39-05 [19]. Three specimens were used for each test. 
The noise insulation performance of the acoustic products was evaluated by the sound absorption coefficients and noise reduction coefficients (NRCs). The sound absorption coefficient was determined in a Kundt tube or impedance tube, with specimens oriented to the axis (Figure 2), following the transfer-function method described in the standard EN ISO 10534-2 [20], at a frequency range of 0-5000 Hz. The sound absorption coefficient was given as the average value obtained after testing each specimen three times. The NRC was measured as the arithmetic average of the sound absorption coefficients determined in the Kundt tube at 250, 500, 1000 and $2000 \mathrm{~Hz}$.
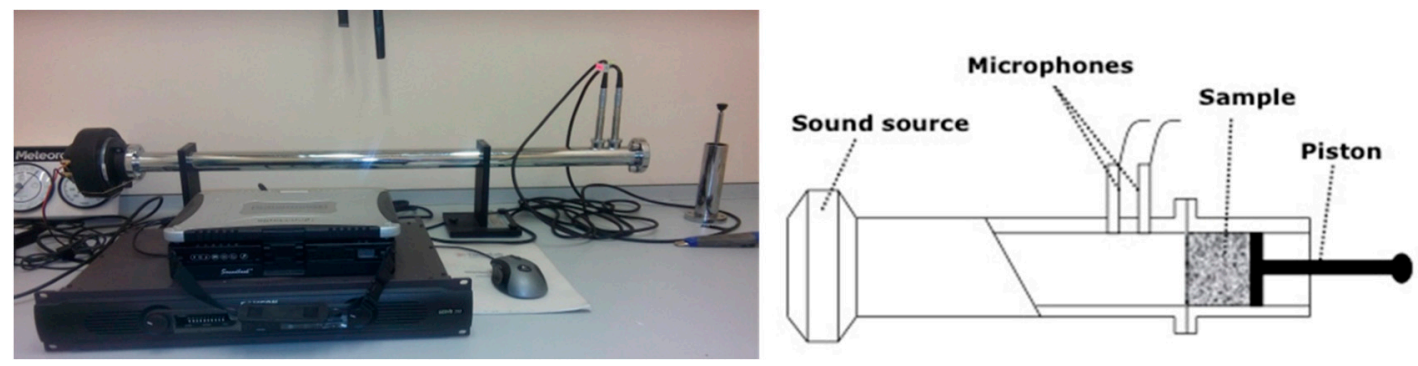

Figure 2. Measurement of sound absorption coefficient by impedance tube.

Batch and monolithic leaching tests were carried out to evaluate the potential environmental implication of the products during their practical use as road acoustic materials. The EN 12457-4 leaching test [21], a batch static extraction test with a liquid/solid ratio of $10 \mathrm{~L} / \mathrm{kg}$ with $24 \mathrm{~h}$ of agitation, was performed on both the boiler slag and acoustic materials. The NEN 7375 diffusion test is a monolithic test [22] and was performed on the final products. It is worth noting that, in order to simulate rain, the principal leaching factor in construction materials, the leaching fluid $($ at $\mathrm{pH}=7)$ was renewed eight times during the NEN 7375 test.

The concentration of most major and trace elements in the leachates was measured by inductively coupled plasma-atomic emission spectrometry (ICP-AES) and inductively coupled plasma mass spectrometry (ICP-MS).The concentration of mercury and major anion species was measured with a gold amalgam atomic absorption spectrometer (GA-AAS) and high-performance liquid chromatography (HPLC).It is worth noting that the NEN 7345 diffusion test for monolith samples could not be conducted on the MS-C acoustic products because they were broken into fine grains when crushed.

\section{Results and Discussion}

\subsection{Physical and Mechanical Properties}

The results obtained for the density, VR and compressive strength of the acoustic products are shown in Table S1 of the supplementary file. The density of the acoustic materials increased with the decrease in the grain size, ranging from the lowest at $1.02 \mathrm{~g} / \mathrm{cm}^{3}$ in MS-C to the highest at $1.28 \mathrm{~g} / \mathrm{cm}^{3}$ in MS-F (Table S1 and Figure 3).Although lower than that of the coarse porous cement (CC, Table S1), the density of the products was similar to that of the comparable bottom-ash-based acoustic products used asnoise barriers $[7,8]$.

Regarding the compressive strength, the values measured for the products were relatively lower than those of the CC (4.0 MPa) and those obtained for similar products using Spanish bottom ash $(<5 \mathrm{MPa})$ [6-8]. The compressive strength increased with the decrease in grain size, and the MS-F made from the fine fraction of the boiler slag had the highest compressive strength with respect to MS-C and MS-M (Table S1 and Figure 4). 


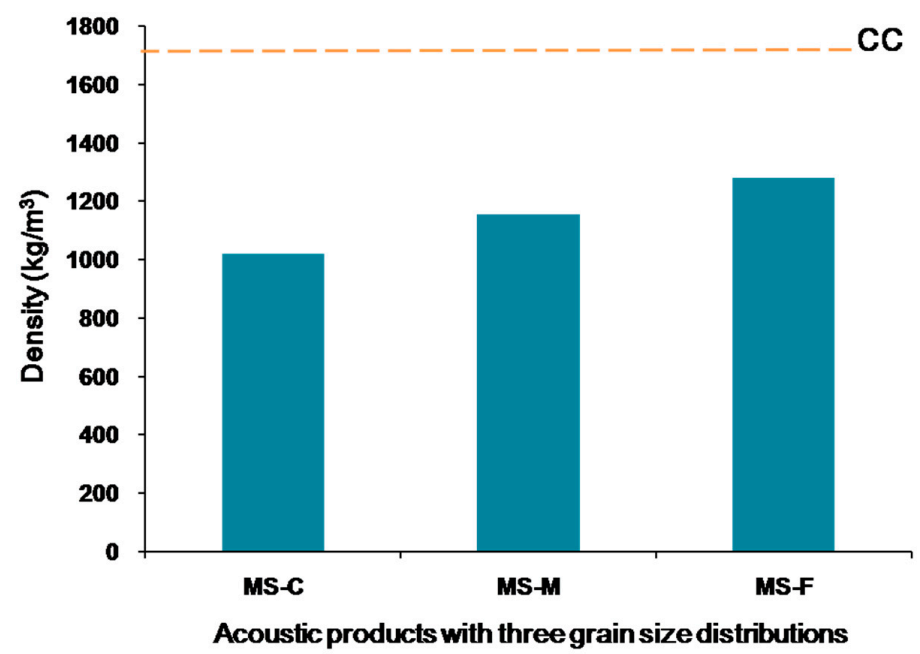

Figure 3. Density of the MS-C, MS-M and MS-F acoustic products compared with coarse porous cement (CC).

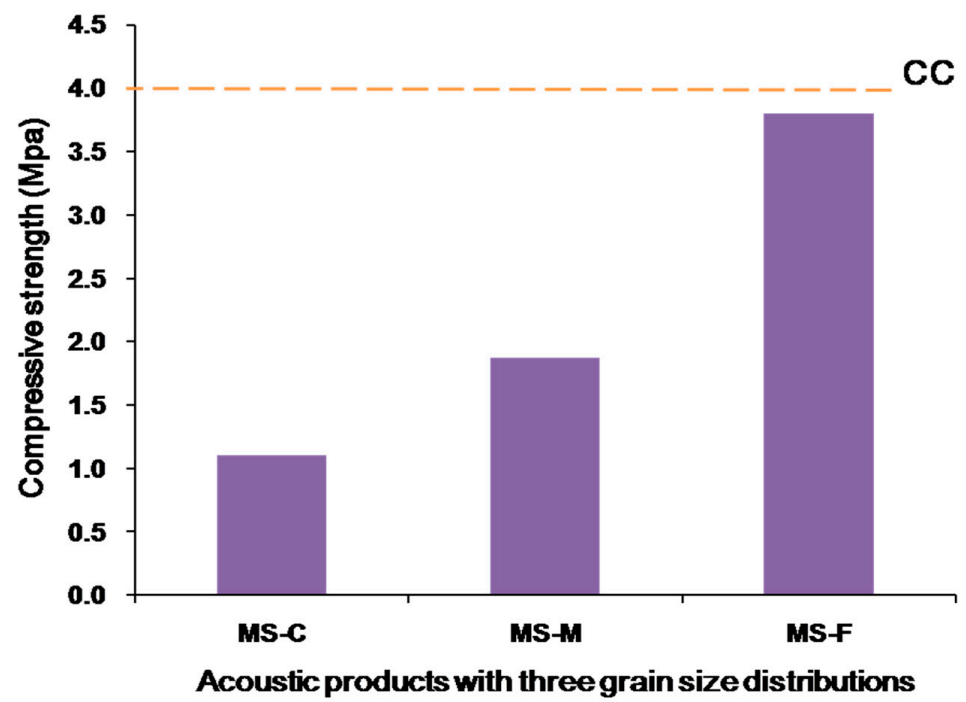

Figure 4. Compressive strength of the three acoustic products compared with coarse porous cement (CC).

In contrast, the VR of the three acoustic products increased with the decrease in the grain size, with MS-C, MS-M and MS-F obtaining VRs of 42\%, 36\% and 18\%, respectively (Table S1 and Figure 5), which was obviously due to there being less void space between particles with smaller grain sizes [6]. When compared with similar products made from bottom ash from a Spanish power plant, VR of the three acoustic products was relatively higher than that of the products with the same grain sizes [6,7].Furthermore, VR of the MS-C and MS-M products was even higher than that of the CC (26\%, Table S1 and Figure 5). 


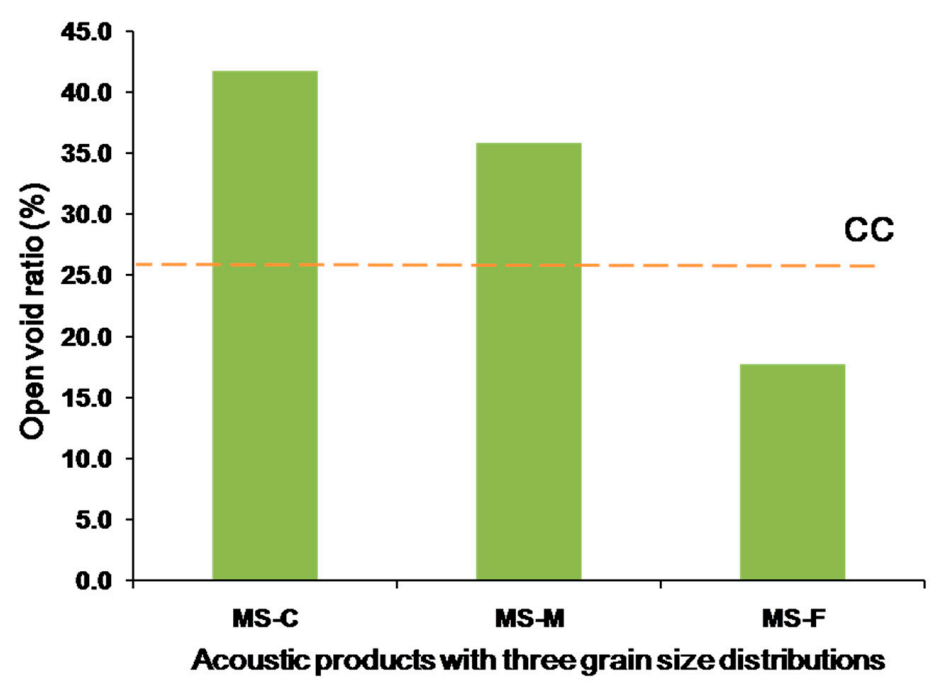

Figure 5. Open void ratio of the three acoustic products compared with coarse porous cement (CC).

\subsection{Acoustic Properties}

The sound absorption coefficients at the main frequency and the calculated noise reduction coefficients (NRCs) of the three noise barrier products made from the three fractions of slag with different sizes are listed in Table S2.

Sound absorption curves of the three products compared with coarse porous cement are illustrated in Figure 6. With respect to MS-C and MS-M, the sound absorption coefficients are very low in the low frequency (Figure 6). However, there are two obvious sound absorption peaks in the mediumand high-frequency ranges (around 1500 and $4000 \mathrm{~Hz}$, respectively), and they present a similar sound absorption behavior at high frequencies. Furthermore, when compared with coarse porous cement, MS-C and MS-M present a better absorption coefficient than CC at low and high frequencies but a similar one at medium frequencies (Figure 6).By contrast, the MS-F product shows extremely low sound absorption coefficients in all the frequency ranges (Figure 6).

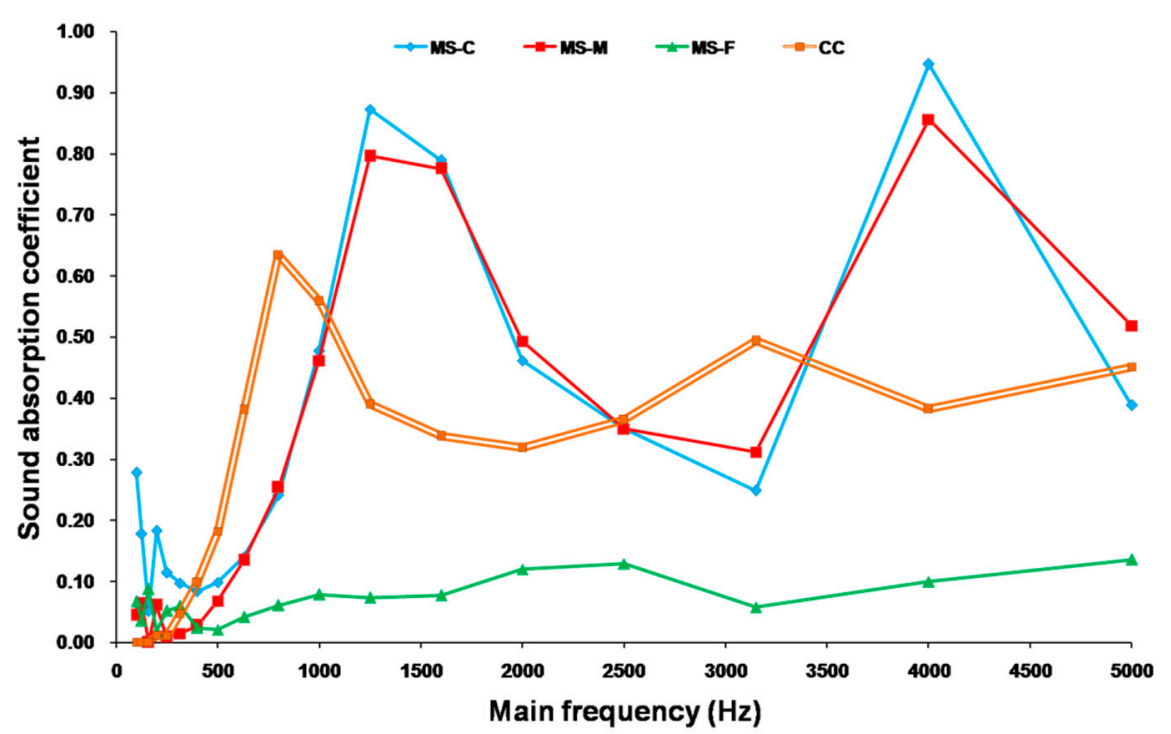

Figure 6. Sound absorption coefficients for noise barrier products made from the studied boiler slag compared with coarse porous cement (CC).

With respect to the noise reduction coefficient, it was positively proportional to the grain size of boiler slag, with the highest NRC obtained from the coarse product MS-C (0.29, Table S2 and Figure 7). 
The NRCs of the manufactured products was relatively lower than those of their counterparts made from Spanish bottom ash [6]. However, the NRCs of the MS-C and MS-M, which presented similar values to that of the coarse porous concrete, were still high enough to reduce the noise $\left(\mathrm{NRC}_{\mathrm{CC}}=0.27\right.$, Table S2 and Figure 7).

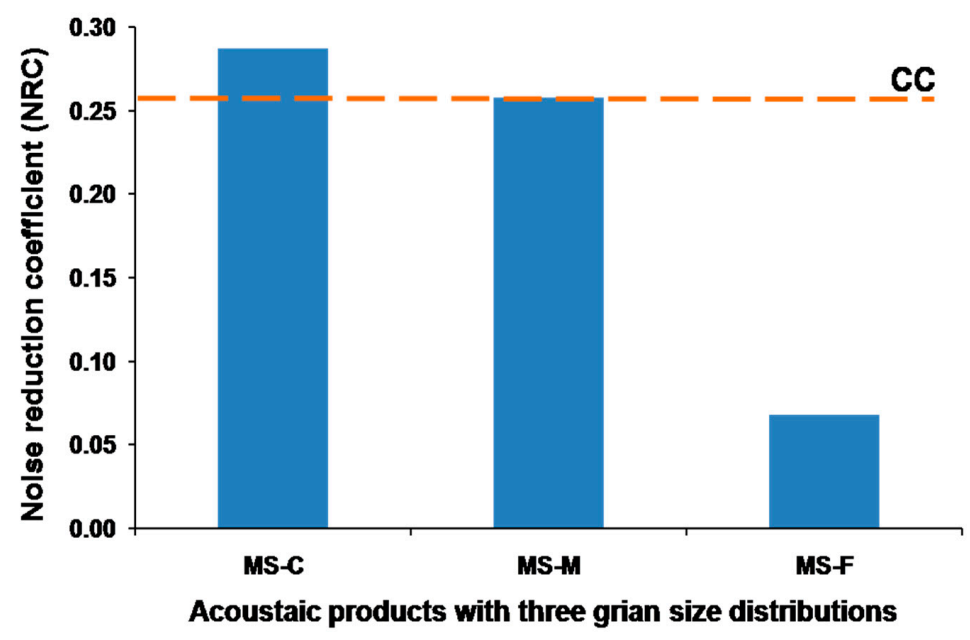

Figure 7. Noise reduction coefficients (NRCs) of the three acoustic products compared with coarse porous cement (CC).

It was obvious that grain size of the boiler slags hasa high influence on the acoustic behavior of the noise barrier products made from them. When the particulate size increased, the sound absorption capacity also increased (Figure 6) due to the high porosity of the produced materials, which was evidenced by the density and VR of these noise barrier products (Table S1). Consequently, the noise materials from MS-C with the largest particle sizes had the largest void space between particles and presented the highest sound absorption coefficients in most frequency ranges apart from 1500 and $4000 \mathrm{~Hz}$.

When compared with some similar products made from bottom ash from power plants, the distributions of sound absorption coefficients for the three studied products were different from those of their counterparts made from Spanish bottom ash [6,7], and the MS-C and MS-M products presented two high sound absorption peaks at low frequency. Furthermore, as previously mentioned, the studied products showed higher VR with respect to the noise materials made from the Spanish bottom ash. Noise materials with larger void space are generally expected to have a high noise absorption coefficient. Nonetheless, despite the higher VR, the manufactured acoustic products (including CC), were characterized by relatively lower noise reduction coefficients, most probably due to their low sound absorption peaks at low frequency [23].

\subsection{Environmental Features}

\subsubsection{EN 12457 Leaching Test}

The ionic conductivities of the leachates obtained from the EN 12457 leaching test increased with the increase in grain sizes of the boiler slag (Table 2). The highest leachate value was obtained from the MS-C acoustic product, probably due to the increasing leachable potential of Ca with the grain size. The leachates of the three acoustic barrier products are characterized by a relatively high alkalinity (10.3-10.9, Table 3), due to the alkalinity of the cement and slag (9.3-9.7) used as the starting materials [24], which fall within the nonhazardous limit for landfill materials regulated by the European Council Decision [25]. 
Table 2. The conductivity $(\mu \mathrm{S} / \mathrm{cm})$ and concentrations $(\mathrm{mg} / \mathrm{kg})$ of major and trace element sin the EN-12457 leachates from three acoustic products.

\begin{tabular}{cccccccc}
\hline & MS-C & MS-M & MS-F & $\mathbf{m g} / \mathbf{k g}$ & MS-C & MS-M & MS-F \\
\hline $\mathrm{K}(\mu \mathrm{S} / \mathrm{cm})$ & 3664 & 2443 & 1523 & $\mathrm{Ti}$ & $<\mathrm{dl}$ & $<\mathrm{dl}$ & $<\mathrm{dl}$ \\
\hline $\mathrm{Al}$ & 6.7 & 6.5 & 8.9 & $\mathrm{~V}$ & 0.01 & 0.05 & 0.3 \\
\hline $\mathrm{Ca}$ & 3875 & 2478 & 1253 & $\mathrm{Mn}$ & $<\mathrm{dl}$ & $<\mathrm{dl}$ & $<\mathrm{dl}$ \\
\hline $\mathrm{Fe}$ & $<\mathrm{dl}$ & $<\mathrm{dl}$ & $<\mathrm{dl}$ & $\mathrm{Co}$ & $<\mathrm{dl}$ & $<\mathrm{dl}$ & $<\mathrm{dl}$ \\
\hline $\mathrm{K}$ & 144 & 164 & 385 & $\mathrm{Ga}$ & 0.02 & 0.03 & 0.04 \\
\hline $\mathrm{Mg}$ & $<\mathrm{dl}$ & $<\mathrm{dl}$ & 0.02 & $\mathrm{Ge}$ & $<\mathrm{dl}$ & 0.01 & $<\mathrm{dl}$ \\
\hline $\mathrm{Na}$ & 45 & 59 & 211 & $\mathrm{Rb}$ & 0.4 & 0.4 & 1.2 \\
\hline $\mathrm{S}$ & 29 & 32 & 59 & $\mathrm{Sr}$ & 11 & 6.6 & 7.6 \\
\hline $\mathrm{P}$ & 0.5 & $<\mathrm{dl}$ & 1.4 & $\mathrm{Zr}$ & $<\mathrm{dl}$ & $<\mathrm{dl}$ & $<\mathrm{dl}$ \\
\hline $\mathrm{Si}$ & 8 & 17 & 55 & $\mathrm{Nb}$ & $<\mathrm{dl}$ & $<\mathrm{dl}$ & $<\mathrm{dl}$ \\
\hline $\mathrm{Li}$ & 0.1 & 0.1 & 0.4 & $\mathrm{Sn}$ & 0.01 & $<\mathrm{dl}$ & $<\mathrm{dl}$ \\
\hline $\mathrm{Be}$ & $<\mathrm{dl}$ & $<\mathrm{dl}$ & $<\mathrm{dl}$ & $\mathrm{Cs}$ & 0.01 & 0.01 & 0.03 \\
\hline $\mathrm{B}$ & 1.2 & 0.8 & 0.5 & $\mathrm{Hf}$ & $<\mathrm{dl}$ & $<\mathrm{dl}$ & $<\mathrm{dl}$ \\
\hline $\mathrm{Sc}$ & $<\mathrm{dl}$ & $<\mathrm{dl}$ & $<\mathrm{dl}$ & $\mathrm{U}$ & $<\mathrm{dl}$ & $<\mathrm{dl}$ & $<\mathrm{dl}$ \\
\hline & & $\mathrm{Abbreviation:}<\mathrm{dl}:$ under detected limit. & &
\end{tabular}

Table 3. Concentrations of potentially hazardous elements in the EN-12457 leachates of the acoustic materials compared with2003/33/CE limit [25].

\begin{tabular}{|c|c|c|c|c|c|c|}
\hline \multirow{2}{*}{$\mathrm{mg} / \mathrm{kg}$} & \multirow{2}{*}{ MS-C } & \multirow{2}{*}{ MS-M } & \multirow{2}{*}{ MS-F } & \multicolumn{3}{|c|}{ 2003/33/CE Limit } \\
\hline & & & & Inert & Nonhazardous & Hazardous \\
\hline $\mathrm{pH}$ & 10.9 & 10.3 & 10.5 & & $>6$ & \\
\hline $\mathrm{Cr}$ & 2.3 & 3.2 & 3.3 & 0.5 & 10 & 70 \\
\hline $\mathrm{Ni}$ & 0.07 & 0.04 & 0.02 & 0.4 & 10 & 40 \\
\hline $\mathrm{Cu}$ & 0.01 & 0.01 & $<\mathrm{dl}$ & 2.0 & 50 & 100 \\
\hline $\mathrm{Zn}$ & $<\mathrm{dl}$ & $<\mathrm{dl}$ & $<\mathrm{dl}$ & 4.0 & 50 & 200 \\
\hline As & $<\mathrm{dl}$ & $<\mathrm{dl}$ & $<\mathrm{dl}$ & 0.5 & 2.0 & 25 \\
\hline Se & 0.02 & 0.02 & 0.03 & 0.1 & 0.5 & 7.0 \\
\hline Mo & 0.3 & 0.5 & 0.7 & 0.5 & 10 & 30 \\
\hline $\mathrm{Cd}$ & $<\mathrm{dl}$ & $<\mathrm{dl}$ & $<\mathrm{dl}$ & 0.04 & 1.0 & 5.0 \\
\hline $\mathrm{Sb}$ & $<\mathrm{dl}$ & $<\mathrm{dl}$ & 0.01 & 0.06 & 0.7 & 5.0 \\
\hline $\mathrm{Ba}$ & 3.1 & 1.7 & 1.4 & 2.0 & 100 & 300 \\
\hline $\mathrm{Pb}$ & 0.02 & 0.01 & $<\mathrm{dl}$ & 0.5 & 10 & 50 \\
\hline $\mathrm{Hg}$ & 0.002 & 0.002 & 0.003 & 0.01 & 0.2 & 2.0 \\
\hline $\mathrm{F}^{-}$ & 10 & 11 & 10 & 10 & 150 & 500 \\
\hline $\mathrm{Cl}^{-}$ & 7.8 & 33 & 61 & 800 & 15,000 & 25,000 \\
\hline $\mathrm{SO}_{4}{ }^{2-}$ & 87 & 96 & 178 & 1000 & 20,000 & 50,000 \\
\hline
\end{tabular}

Most major and trace elements show relatively low leaching potential from the acoustic products (Tables 2 and 3), except for high leaching concentrations of $\mathrm{Sr}$ and Ba due to their high concentrations in feed coal [24]. Regarding some trace elements of potential environmental concern, concentrations of $\mathrm{Cr}$, Mo and $\mathrm{Ba}$ in the leachates fall within the nonhazardous limit, and those of $\mathrm{SO}_{4}{ }^{2-}$ and other 
toxic elements fall within the inert limit of landfills regulated by the European Council Decision 2003/33/CE [25] (Table 3). In addition, the leachable concentration of these elements is also much lower than the maximum hazardous limit regulated for Chinese hazardous wastes [26]. Therefore, these acoustic products can be classified as nonhazardous materials, indicating no environmental implications during their practical application.

\subsubsection{NEN 7345 Leaching Test}

With respect to the NEN tank leaching tests (Table 4), the leachable concentrations of these elements of environmental concern are all far below the Decree on Soil Quality (DSQ) limits regulated for bound or shaped materials [27]. That is to say, from both EN and NEN leaching tests, the acoustic materials made from the studied boiler slag can be widely used for further production of acoustic barriers without environmental threat.

Table 4. Concentrations of potentially hazardous elements in the NEN 7345 leachates of the MS-M and MS-F acoustic materials compared with the DSQ limit [27].

\begin{tabular}{cccc}
\hline $\mathbf{m g} / \mathbf{m}^{2}$ & MS-M & MS-F & DSQ Limit ${ }^{*}$ \\
\hline $\mathrm{As}$ & 0.2 & 0.5 & 260 \\
\hline $\mathrm{Ba}$ & 7.6 & 5.4 & 1500 \\
\hline $\mathrm{Cd}$ & $<\mathrm{dl}$ & $<\mathrm{dl}$ & 3.8 \\
\hline $\mathrm{Co}$ & $<\mathrm{dl}$ & $<\mathrm{dl}$ & 60 \\
\hline $\mathrm{Cr}$ & 17 & 17 & 120 \\
\hline $\mathrm{V}$ & 13 & 12 & 320 \\
\hline $\mathrm{Mo}$ & 2.1 & 4.1 & 144 \\
\hline $\mathrm{Cu}$ & $<\mathrm{dl}$ & $<\mathrm{dl}$ & 98 \\
\hline $\mathrm{Ni}$ & 0.1 & $<\mathrm{dl}$ & 81 \\
\hline $\mathrm{Pb}$ & $<\mathrm{dl}$ & $<\mathrm{dl}$ & 400 \\
\hline $\mathrm{Zn}$ & 0.8 & 0.2 & 800 \\
\hline $\mathrm{Se}$ & 0.1 & 0.04 & 4.8 \\
\hline $\mathrm{Sn}$ & $<\mathrm{dl}$ & $<\mathrm{dl}$ & 50 \\
\hline $\mathrm{Sb}$ & 0.3 & 0.4 & 8.7 \\
\hline
\end{tabular}

Abbreviations: *, data from Decree of Soil Quality [27]; <dl, under detected limit.

\section{Conclusions}

Three acoustic materials to be used as acoustic barriers were successfully manufactured from mixtures of $20 \%$ Portland cement type II and up to $80 \%$ boiler slag (from Xinjiang PCC power plants) with different grain sizes.

First, the grain size of the boiler slag had a big influence on various properties of the acoustic products. The density and the compressive strength of the products were inversely proportional, but the sound absorption coefficients and NRC were positively correlated with the grain size of the boiler slag. Accordingly, the MS-C acoustic product made from the coarsest fraction of the boiler slag showed the best sound absorption and reduction performance, which was caused by the highest open void ratio. The highest open void ratio led to the reduction of a large proportion of noise due to energy loss by means of the friction in the void.

Second, the acoustic products presented comparable density and compressive strength to similar acoustic products made of a combination of Spanish bottom ash and conventional or recycled materials. The MS-C and MS-M acoustic barrier products presented good noise absorption characteristics, comparable to those of the counterpart acoustic products made from Spanish bottom ash and to 
those of commercial coarse porous cement, which is traditionally used in this application. Durability aspects (thermal, fire, freeze-thaw, acid attack, carbonation, corrosion, sulfate attack, chloride, abrasion, impacts, vibrations), although very interesting and important, required a high number of samples and more time to study. We are carrying out this study but, at this time, we do not have all the results, and the work will take a very long time.

Third, from an environmental point of view, the EN 12457 leaching test indicated that most of the elements in the manufactured acoustic barrier products, including those of potential environmental concern, showed very low leaching potential, falling within the range of the nonhazardous limit for hazardous waste landfills regulated by both European and Chinese standards. Furthermore, the accumulated contents of those toxic elements in the leachates of acoustic products after the 64-day NEN 7345 leaching test were far below the DSQ limits regulated for bound or shaped materials.

Overall, manufacturing acoustic materials is a promising utilization of boiler slag with low economic costs and no environmental burden but high added values. To optimize the sound absorption coefficient of the acoustic materials, further research will focus on manufacturing multilayer noise barriers developed with all three fractions of the boiler slag with different particle sizes.

Supplementary Materials: The following are available online at http://www.mdpi.com/1996-1073/13/21/5705/s1, Table S1: Density, compressive strength, and open void ratio of the acoustic barrier products, Table S2. The sound absorption coefficients at the main frequencies and the noise reduction coefficients (NRC) of the three noise barrier products.

Author Contributions: Conceptualization, J.L. and X.Z.; methodology, J.L., C.L., C.A. and A.C.; investigation, J.L., O.F. and N.M.; writing—original draft preparation, J.L.; writing—review and editing, X.Q. and N.M.; supervision, X.Z., X.Q. and C.F.P.; project administration, J.L. All authors have read and agreed to the published version of the manuscript.

Funding: The present research is funded by the National Science Foundation of China (Nos. 41972179, 41972180), the National Key R\&D Program of China (No. 2018YFF0215400) and the Fundamental Research Funds for the Central Universities, China University of Geosciences (Wuhan) (No. CUGCJ1819).

Acknowledgments: The authors express sincere gratitude to the Huadian Power Corporation in Xinjiang, China for assistance in collecting the boiler slag samples and express great appreciation to the University of Seville for providing laboratory and instruments for manufacturing and property-testing of the acoustic products.

Conflicts of Interest: There is no conflict of interest.

\section{References}

1. Nelson, P.M.; Phillips, S.M. Designing Porous Road Surfaces to Reduce Traffic Noise, TRL Annual Review; Transportation Research Laboratories: Berkshire, UK, 1994.

2. Kim, H.; Lee, H. Influence of cement flow and aggregate type on the mechanical and acoustic characteristics of porous concrete. Appl. Acoust. 2010, 71, 607-615. [CrossRef]

3. Park, S.B.; Seo, D.S.; Lee, J. Studies on the sound absorption characteristics of porous concrete based on the content of recycled aggregate and target void ratio. Cem. Concr. Res. 2005, 35, 1846-1854. [CrossRef]

4. Park, S.B.; Jang, Y.I.; Lee, J.; Lee, B.J. An experimental study on the hazard assessment and mechanical properties of porous concrete utilizing coal bottom ash coarse aggregate in Korea. J. Hazard. Mater. 2009, 166, 348-355. [CrossRef] [PubMed]

5. Lee, H.; Kim, H.; Hwang, E. Utilization of power plant bottom ash as aggregates in fiber-reinforced cellular concrete. Waste Manag. 2010, 30, 274-284. [CrossRef] [PubMed]

6. Arenas, C.; Leiva, C.; Luis, F.; Jose, V. Development of acoustic barriers mainly composed of co-combustion bottom ash. In Proceedings of the World of Coal Ash WOCA Conference, Denver, CO, USA, 9-12 May 2011.

7. Arenas, C.; Leiva, C.; Vilches, L.; Cifuentes, H. Use of co-combustion bottom ash to design an acoustic absorbing material for highway noise barriers. Waste Manag. 2013, 33, 2316-2321. [CrossRef] [PubMed]

8. Arenas, C.; Leiva, C.; Vilches, L.F.; Cifuentes, H.; Rodríguez-Galán, M. Technical specifications for highway noise barriers made of coal bottom ash-based sound absorbing concrete. Constr. Build. Mater. 2015, 95, 585-591. [CrossRef] 
9. Arenas, C. Recycling coal bottom ash in construction materials. Technical Specifications of Bottom Ash-Based Sound Absorbing Porous Concrete Applied in Highway Noise Barriers. Ph.D. Thesis, University of Seville, Seville, Spain, 2013.

10. Cox, M.; Nugteren, H.; Janssen-Jurkovičová, M. Combustion Residues-Current, Novel and Renewable Applications; Wiley: Chichester, UK, 2008.

11. Fu, J. Challenges to Increased Use of Coal Combustion Products in China. Master's Thesis, Linköping University, Linköping, Sweden, 2010.

12. NCASI. National Council for Air and Stream Improvement, Beneficial Use of Industrial by-Products. 2003. Available online: http://www.industrialmaterialssummit.com/midwest/summit/rmt_rpt.pdf (accessed on 28 May 2020).

13. Li, J.; Zhuang, X.; Querol, X.; Font, O.; Moreno, N. A review on the applications of coal combustion products in China. Int. Geol. Rev. 2017, 60, 671-716. [CrossRef]

14. BP. Statistical Review of World Energy. 2020. Available online: https://www.bp.com/content/dam/bp/businesssites/en/global/corporate/pdfs/energy-economics/statistical-review/bp-stats-review-2020-full-report.pdf (accessed on 30 June 2020).

15. Li, J.; Zhuang, X.; Font, O.; Moreno, N.; Vallejo, R.; Querol, X.; Tobías, A. Synthesis of merlinoite from Chinese coal fly ashes and its potential utilization as slow release K-fertilizer. J. Hazard. Mater. 2014, 265, $242-252$. [CrossRef] [PubMed]

16. Li, J.; Zhuang, X.; Leiva, C.; Cornejo, A.; Font, O.; Querol, X.; Moeno, N.; Arenas, C.; Fernández-Pereira, C. Potential utilization of FGD gypsum and fly ash from a Chinese power plant for manufacturing fire-resistant panels. Constr. Build. Mater. 2015, 95, 910-921. [CrossRef]

17. Li, J.; Zhuang, X.; Monfort, E.; Querol, X.; Llaudis, A.S.; Font, O.; Moreno, N.; Ten, F.J.G.; Izquierdo, M. Utilization of coal fly ash from a Chinese power plant for manufacturing highly insulating foam glass: Implications of physical, mechanical properties and environmental features. Constr. Build. Mater. 2018, 175, 64-76. [CrossRef]

18. EN-1936. Determinación de la Densidad Real y Aparentey de la Porosidadabiertay Tota; CEN: Brussels, Belgium, 2006.

19. ASTM C39-05. Standard Test Method for Compressive Strength of Cylindrical Concrete Specimens; ASTM International: West Conshohocken, PA, USA, 2005.

20. EN ISO 10534-2. Acoustics Determination of Sound Absorption Coefficient and Impedance or Admittance by the Impedance tube. Part II: Transfer Function Method; Rue de Stassart: Brussels, Belgium, 1998.

21. EN 12457-4. Characterization of Waste: Leaching. Compliance Test for Leaching of Granular waste Material and Sludges. Part 2: OneStage Batch Test at a Liquid to Solid Ratio of $10 \mathrm{l} / \mathrm{kg}$ for Materials with Particle Size Below10 mm (without or with Size Reduction); Rue de Stassart: Brussels, Belgium, 2003.

22. NEN 7345. Leaching Characteristics of Soil and Stony Building and Waste Materials-Leaching test-Determination of the Leaching of Inorganic Components from Building and Monolithic Waste Materials with the Diffusion Test; Netherlands Standards: Delft, The Netherlands, 1995.

23. Möser, M.; Barros, J.L. IngenieríaAcústica. Teoría y Aplicaciones, 2nd ed.; Springer: Berlin, Germany, 2009.

24. Li, J.; Zhuang, X.; Querol, X.; Font, O.; Moreno, N.; Zhou, J. Environmental geochemistry of the feed coals and their combustion by-products from two coal-fired power plants in Xinjiang Province, Northwest China. Fuel 2012, 95, 446-456. [CrossRef]

25. European Council Decision 2003/33/EC. Off. J. Eur. Commun. 2003, 16, 27-49.

26. GB 18598-2001. Standard for Pollution Control on Security Landfill Site for Hazardous Wastes; State Environmental Protection Administration: Beijing, China, 2001.

27. Decree on Soil Quality, Besluit van 22 November 2007, houdende regels inzake de kwaliteit van de bodem (Besluitbodemkwaliteit); Belgisch Staatsblad: Brussel, Belgium, 2007; p. 469.

Publisher's Note: MDPI stays neutral with regard to jurisdictional claims in published maps and institutional affiliations. 